\title{
Análise de crescimento de gérbera de vaso conduzida em diferentes substratos
}

\author{
Fernanda Ludwig; Amaralina C Guerrero; Dirceu M Fernandes; Roberto L Villas Boas
}

UNESP-FCA, Dep to Recursos Naturais, Ciência do Solo, C. Postal 237, 18610-307 Botucatu-SP; ludwig.fernanda@yahoo.com.br; amaralina@fca.unesp.br; dmfernandes@fca.unesp.br; rlvboas@fca.unesp.br.

\section{RESUMO}

O cultivo e o comércio de gérbera em vaso são recentes e há uma grande demanda quanto à seleção de substratos adequados à sua produção. O presente trabalho foi desenvolvido com o objetivo de avaliar o crescimento de duas cultivares de gérbera de vaso, conduzidas com diferentes substratos. O experimento foi realizado em casa de vegetação entre setembro e novembro de 2008, em Botucatu-SP. $\mathrm{O}$ delineamento experimental utilizado foi de blocos ao acaso em esquema fatorial $5 \times 2$ (substratos x cultivares) e quatro repetições. Plantas de gérbera, cultivares Cherry e Red, foram avaliadas quinzenalmente $(1,15,29$ e 43 dias após aclimatação (DAA)) quanto à área foliar e a fitomassa seca da parte aérea, as quais foram ajustadas em relação ao tempo com o programa ANACRES para obtenção da razão da área foliar (RAF), taxa de crescimento relativo (TCR) e taxa de assimilação líquida (TAL). As plantas de gérbera apresentaram melhor desenvolvimento quando conduzidas no substrato $4(30 \%$ casca de pinus, $30 \% \mathrm{C}_{1}, 20 \%$ fibra de coco granulada, $20 \%$ fibra de coco mista). A seleção de substratos adequados ao desenvolvimento de gérbera deve considerar, principalmente, as características químicas e físicas dos mesmos. Para as cultivares estudadas, valores de $\mathrm{pH}$ do substrato inferiores a 5,5 e superiores a 7,0 foram inadequados para o desenvolvimento, bem como densidades úmidas superiores a $530 \mathrm{~kg} \mathrm{~m}^{-3}$.

\begin{abstract}
Growth analysis of potted gerbera grown in different substrates

Cultivation and commercialization of potted gerbera are recent issues and there is a great demand for adequate substrates for its production. This work aimed to evaluate the growth of two potted gerbera cultivars (Cherry and Red) grown in different substrates. The experiment was carried out in a greenhouse from September to November 2008 at Botucatu, São Paulo State, Brazil. Experimental design was randomized blocks in a $5 \times 2$ factorial arrangement (substrates x cultivars). Gerbera plants leaf area and dry phytomass were evaluated fortnightly $(1,15,29$ and 43 days after acclimation (DAA)). For the leaf area ratio (RAF), relative growth rate (TCR) and net assimilation rate (TAL), the total dry phytomass and leaf area were adjusted in relation to time using the ANACRES program. The gerbera plants had better development in substrate 4 (30\% pinus bark, $30 \% \mathrm{C}_{1}, 20 \%$ granulated coconut, $20 \%$ mixed coconut). The selection of substrates for the development of gerbera plants should consider primarily its physical and chemical attributes. For the studied cultivars, the substrate $\mathrm{pH}$ below 5.5 and above 7.0 was unsuitable for development as well as dry densities above $530 \mathrm{~kg} \mathrm{~m}^{-}{ }^{3}$.
\end{abstract}

Palavras-chave: Gerbera jamesonii, floricultura, cultivo sem solo.

Keywords: Gerbera jamesonii, floriculture, soilless.

\section{(Recebido para publicação em 21 de setembro de 2009; aceito em 22 de fevereiro de 2010) (Received on September 21, 2009; accepted on February 22, 2010)}

\begin{abstract}
A gérbera é uma planta herbácea, com inflorescência em capítulo, pertencente à classe das dicotiledôneas $\mathrm{e}$ família Asteraceae. É originária da África do Sul onde cresce espontaneamente em áreas sombreadas, ausente de luz direta (Mercurio, 2002). Inicialmente, restringia-se à flor de corte, cultivada diretamente em solo, sendo recente seu comércio como flor envasada. Com isso, há crescente demanda pela seleção de substratos adequados a cada cultivo.

O substrato contribui para o crescimento de plantas cultivadas, principalmente pelo reduzido espaço para crescimento das raízes. Bellé (2001) afirma que os substratos bem aerados permitem o bom desenvolvimento de pêlos radiculares finos e de ramificações de raízes, o que aumenta a absorção de nutrientes. Aágua, um outro componen-
\end{abstract}

te do substrato, atua na fotossíntese, absorção de nutrientes, transporte e síntese de hormônios, entre outros processos fisiológicos. Desse modo, é importante estabelecer uma adequada relação entre ar e água do substrato a ser utilizado.

Trabalhos desenvolvidos com gérbera de corte sugerem que a produção em substratos com maior aeração na zona radicular e melhor drenagem da água de irrigação apresentam resultados positivos, como maior precocidade, número de flores por planta e uniformidade na qualidade comercial das flores (Lenzi et al., 1998; Mascarini, 1998). Quanto às características químicas do substrato, a gérbera parece ser influenciada diretamente pelo $\mathrm{pH}$ e segundo recomendações obtidas na literatura, o $\mathrm{pH}$ pode ser mantido entre 5,5 e 6,5 (Rogers \& Tjia, 1990), entretanto, autores relatam que o
pH acima de 6,0 provoca diminuição da produção em plantas de gérbera (Sonneveld \& Voogt, 1997; Savvas \& Givas, 2002). Essas informações indicam que substratos com diferentes características físicas e químicas podem interferir no crescimento de plantas de gérbera.

A análise de crescimento se baseia fundamentalmente no fato de que cerca de $90 \%$, em média, da fitomassa seca acumulada pelas plantas, ao longo do seu crescimento resulta da atividade fotossintética. Essa análise expressa as condições morfofisiológicas da planta e avalia sua produção líquida, derivada do processo fotossintético, resultado do desempenho do sistema assimilatório durante certo período de tempo (Benincasa, 2003) e contribui para uma visão mais detalhada e até econômica de uma cultura (Charlo, 2008). 
O presente trabalho foi desenvolvido com o objetivo de avaliar o crescimento de plantas de gérbera de vaso, cultivares Red e Cherry, conduzidas com diferentes substratos.

\section{MATERIAL E MÉTODOS}

O experimento foi conduzido em casa de vegetação, de setembro a novembro de 2008 , em Botucatu (22 $51^{\prime}$ 'S e $\left.48^{\circ} 26^{\prime} \mathrm{W}\right)$. A temperatura média no interior da casa de vegetação foi de $23^{\circ} \mathrm{C}$ e a umidade relativa média do ar de $63 \%$. $\mathrm{O}$ delineamento experimental utilizado foi de blocos ao acaso, em esquema fatorial $5 \times 2$ ( 5 substratos e 2 cultivares) e quatro repetições.

Os substratos utilizados foram: $1=$ $40 \%$ terra vermelha (Latossolo Vermelho Escuro), 40\% casca de pinus, 10\% composição $1 .\left(\mathrm{C}_{1}\right)=(40 \%$ casca de pinus $+30 \%$ vermiculita $+30 \%$ casca de arroz carbonizada), 10\% composição 2 . $\left(\mathrm{C}_{2}\right)=(75 \%$ casca de pinus $+25 \%$ acícula de pinus); $2=20 \%$ terra vermelha, $30 \%$ casca pinus, $30 \%$ de $\mathrm{C}_{1}, 20 \% \mathrm{C}_{2}$; $3=50 \%$ casca de pinus, $20 \%$ fibra de coco granulada, $30 \% \mathrm{C}_{1} ; 4=30 \%$ casca de pinus, $30 \% \mathrm{C}_{1}, 20 \%$ fibra de coco granulada, 20\% fibra de coco mista; $5=$ substrato comercial $(70 \%$ casca de pinus $+15 \%$ turfa $+15 \%$ vermiculita). As características químicas de $\mathrm{CE}$ e $\mathrm{pH}_{1: 5}$ (Brasil, 2007), macronutrientes e micronutrientes ${ }_{1: 1,5}$ (Sonneveld \& Elderen, 1994), relação C/N e matéria orgânica dos substratos (Raij et al., 2001) e físicas de densidade (Brasil, 2007) e retenção de água (De Boodt \& Verdonck, 1972), são apresentadas na Tabela 1.

Foram utilizadas mudas de gérbera (Gerbera jamesonii L.) com quatro folhas definitivas, cultivares Cherry e Red pertencentes à serie "Dark eyes" da empresa Sakata Seed Sudamérica ${ }^{\circledR}$. As mudas foram transplantadas em vasos com capacidade para $1 \mathrm{~L}(11,5 \mathrm{~cm}$ de altura, $13 \mathrm{~cm}$ de base superior e $9 \mathrm{~cm}$ de base inferior), preenchidos com o substrato correspondente ao tratamento, de acordo com a densidade úmida.

A casa de vegetação apresenta cobertura em arco com plástico transparente de 150 mícron, com laterais de tela branca, cortinas de plástico transparente e pavimentada com concreto, em uma área total de $168 \mathrm{~m}^{2}$ (7 x $\left.24 \mathrm{~m}\right)$ e 2,6 m de pé direito. As plantas foram aclimatadas durante 30 dias, dispostas sobre bancada de madeira (1,2 de largura, 12 de comprimento, $0,8 \mathrm{~m}$ de altura) sob malha termorefletora (Aluminet ${ }^{\circledR}$ ) disposta na parte superior interna da casa de vegetação, que mantinha a intensidade luminosa próxima a 25.000 Lux. Após a aclimatação, os vasos foram espaçados de 25 em $25 \mathrm{~cm}$ e distribuídos em duas bancadas, permanecendo na intensidade luminosa máxima de 50.000 Lux. Em cada bancada foram distribuídos dois blocos, dispostos longitudinalmente, com 11 plantas por parcela, sendo utilizada uma planta em cada coleta. A avaliação experimental iniciou após a aclimatação, encerrando quando as plantas apresentavam características adequadas para a comercialização e os resultados são apresentados em dias após aclimatação (DAA).

O manejo da fertirrigação baseou-se na pesagem diária dos vasos, os quais foram mantidos na faixa de 50 a $25 \%$ da água disponível no substrato. A irrigação foi realizada via solução nutritiva com a seguinte composição em mg L-1: 121 $\mathrm{N}_{-} \mathrm{NO}_{3}^{-}, 12 \mathrm{~N}_{-} \mathrm{NH}_{4}^{+}, 92 \mathrm{~K}, 24 \mathrm{P}, 175 \mathrm{Ca}$, $27 \mathrm{Mg}$ e $39 \mathrm{~S}, 0,19 \mathrm{~B}, 0,08 \mathrm{Cu}, 2,74 \mathrm{Fe}$, 0,19 Mn, 0,04 Mo e 0,08 Zn no período

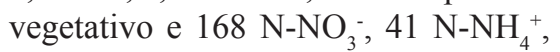
$303 \mathrm{~K}, 35 \mathrm{P}, 105 \mathrm{Ca}, 45 \mathrm{Mg}$ e $55 \mathrm{~S}, 0,19$ B, 0,08 Cu, 2,74 Fe, 0,19 Mn, 0,04 Mo e $0,08 \mathrm{Zn}$ no reprodutivo.

Durante o crescimento vegetativo, como é padrão nas produções comerciais, foram desbastados os botões florais desenvolvidos até os 29 DAA. A área foliar e a fitomassa seca das plantas foram determinadas quinzenalmente aos $1,15,29$ e 43 DAA. A parte aérea da planta foi cortada rente ao substrato e determinou-se a área foliar em medidor modelo Li 3100, da marca Licor. A parte aérea das plantas, separada em folhas e inflorescências no período reprodutivo, iniciado aos 29 DAA, foi seca em estufa de ventilação forçada a $65^{\circ} \mathrm{C}$ por um período de 48 horas, obtendo-se a fitomassa seca em balança digital.

Para obtenção dos índices fisiológicos de razão da área foliar (RAF), taxa de crescimento relativo (TCR) e taxa de assimilação líquida (TAL), as variáveis de fitomassa seca total e área foliar foram ajustadas em relação ao tempo (1, 15, 29 e 43 DAA) com o programa ANACRES (Portes \& Castro Junior, 1991) utilizando a equação exponencial quadrática, que foi a que melhor se ajustou ao conjunto de dados.

Quando as plantas apresentaram inflorescências abertas com características para comercialização, aos 43 DAA, foram avaliadas quanto à fitomassa seca da folha (FSF) e inflorescência (FSI), número de folhas (NF), diâmetro de planta (DP), área foliar (AF), tamanho da folha (TF), número de inflorescência (NI) e diâmetro de inflorescência (DI). O diâmetro de planta foi determinado pela distância entre as extremidades da superfície foliar no vaso, com uso de régua graduada, em duas medidas perpendiculares. $\mathrm{O}$ diâmetro das inflorescências foi aferido com uso de paquímetro digital.

Os resultados foram submetidos à análise de variância pelo teste F. As médias foram comparadas pelo teste Tukey a 5\% de probabilidade. Procedeuse o desdobramento da interação entre substratos e cultivares quando a análise de variância revelou efeito significativo, utilizando o programa estatístico Sisvar (Ferreira, 2000).

\section{RESULTADOS E DISCUSSÃO}

A razão de área foliar (RAF) é a área foliar útil para a fotossíntese, sendo a razão entre a área responsável pela interceptação de energia luminosa e $\mathrm{CO}_{2} \mathrm{e}$ a fitomassa seca total, que é o resultado da fotossíntese (Benincasa, 2003). A RAF foi maior no início do período de avaliação, quando a planta converte maior produção fotossintética para a expansão foliar e captação de luz, declinando seus valores ao longo do ciclo (Figura 1A e B), devido à interferência das folhas superiores sobre as inferiores e redução da área foliar útil para a fotossíntese. Segundo Infoagro (2005), a gérbera tem crescimento em roseta, acarretando na sobreposição das folhas com consequente sombreamento. A partir do período reprodutivo as estruturas não-fotossintetizantes, como as flores, $\mathrm{o}$ auto-sombreamento e a queda de folhas, reduzem os valores desse índice (Urchei et al., 2000). Resultados semelhantes 
Tabela 1. Características químicas e físicas dos substratos utilizados no crescimento e desenvolvimento de gérbera (chemical and physical characteristics of substrates used in the experiment). Botucatu, UNESP. 2008.

\begin{tabular}{|c|c|c|c|c|c|}
\hline \multirow{2}{*}{ Características } & \multicolumn{5}{|c|}{ Substrato } \\
\hline & 1 & 2 & 3 & 4 & 5 \\
\hline $\mathrm{CE}_{1: 5}\left(\mathrm{dS} \mathrm{\textrm {m } ^ { - 1 } )}\right.$ & 0,54 & 0,49 & 0,26 & 0,28 & 0,48 \\
\hline $\mathrm{pH}_{1: 5 \text { (inicial) }}$ & 5,13 & 4,81 & 5,74 & 5,74 & 7,58 \\
\hline $\mathrm{pH}_{1: 5 \text { (final) }}$ & 5,42 & 4,86 & 5,63 & 5,59 & 6,89 \\
\hline MO (\%) & 19,00 & 28,00 & 38,00 & 33,00 & 34,00 \\
\hline $\mathrm{C} / \mathrm{N}$ & 10,55 & 15,55 & 21,11 & 18,33 & 18,88 \\
\hline $\mathrm{K}_{1: 1,5}\left(\mathrm{mg} \mathrm{L}^{-1}\right)$ & 70,25 & 86,00 & 45,43 & 56,70 & 176,25 \\
\hline $\mathrm{Ca}_{1: 1,5}\left(\mathrm{mg} \mathrm{L}^{-1}\right)$ & 52,40 & 84,98 & 3,57 & 22,83 & 21,63 \\
\hline $\operatorname{Mg}_{1: 1,5}\left(\mathrm{mg} \mathrm{L}^{-1}\right)$ & 50,15 & 57,60 & 12,13 & 24,45 & 12,83 \\
\hline $\mathrm{Cu}_{1: 1,5}\left(\mathrm{mg} \mathrm{L}^{-1}\right)$ & 0,01 & 0,02 & 0,06 & 0,03 & 0,06 \\
\hline $\mathrm{Fe}_{1: 1,5}\left(\mathrm{mg} \mathrm{L}^{-1}\right)$ & 0,38 & 0,62 & 5,57 & 1,76 & 1,83 \\
\hline $\mathrm{Mn}_{1: 1,5}\left(\mathrm{mg} \mathrm{L}^{-1}\right)$ & 0,19 & 2,48 & 0,20 & 0,38 & 0,84 \\
\hline $\mathrm{Zn}_{1: 1,5}\left(\mathrm{mg} \mathrm{L}^{-1}\right)$ & 0,04 & 0,11 & 0,06 & 0,06 & 0,08 \\
\hline Porosidade total- PT (\%) & 78,79 & 80,62 & 84,28 & 89,18 & 83,51 \\
\hline Sólidos (\%) & 21,21 & 19,38 & 15,72 & 10,82 & 16,49 \\
\hline Espaço de aeração - EA (\%) & 23,50 & 19,33 & 12,76 & 17,15 & 21,10 \\
\hline Água disponível - AD (\%) & 28,74 & 29,40 & 37,34 & 35,80 & 32,90 \\
\hline Água remanescente - AR (\%) & 26,48 & 31,89 & 34,62 & 36,23 & 29,50 \\
\hline Densidade úmida $\left(\mathrm{kg} \mathrm{m}^{-3}\right)$ & 750,00 & 850,00 & 690,00 & 590,00 & 530,00 \\
\hline Densidade seca $\left(\mathrm{kg} \mathrm{m}^{-3}\right)$ & 538,00 & 540,00 & 450,00 & 298,00 & 340,00 \\
\hline
\end{tabular}

Substratos: $1=40 \%$ terra vermelha (Latossolo Vermelho Escuro (LVE)), 40\% casca de pinus $(\mathrm{CP}), 10 \%$ composição $1\left(\mathrm{C}_{1}\right)(40 \% \mathrm{CP}+30 \%$ vermiculita $(\mathrm{V})+30 \%$ casca de arroz carbonizada), $10 \%$ composição $2\left(\mathrm{C}_{2}\right)(75 \% \mathrm{CP}+25 \%$ acícula de pinus $) ; 2=20 \% \mathrm{LVE}$, $30 \% \mathrm{CP}, 30 \% \mathrm{C}_{1}, 20 \% \mathrm{C}_{2} ; 3=50 \% \mathrm{CP}, 20 \%$ fibra de coco granulada (FCG), $30 \% \mathrm{C}_{1} ; 4=$ $30 \% \mathrm{CP}, 30 \% \mathrm{C}_{1}, 20 \% \mathrm{FCG}, 20 \%$ fibra de coco mista; $5=$ substrato comercial $(70 \% \mathrm{CP}+$ $15 \%$ turfa $+15 \% \mathrm{~V})$.

foram obtidos por Fontes et al. (2005) para a cultura do pimentão e Silva et al. (2009) para o girassol ornamental.

A RAF foi menor nas plantas que cresceram com substratos 1 e 2 em relação aos demais (Figura 1A e B). Para as plantas conduzidas nesses substratos, foi possível constatar reduzido acréscimo da área foliar em relação às demais na fase reprodutiva, iniciada aos 29 DAA, para que as inflorescências pudessem se estabelecer, apresentando menor quantidade de material fotossintetizante em relação à fitomassa seca total. Essa maior redução da RAF pode ter sido decorrente da maior eficiência da folha em converter energia luminosa e $\mathrm{CO}_{2}$ em fitomassa seca, principalmente para as inflorescências, conforme constatado na Tabela 2. A maior conversão da massa para as inflorescências pode ser considerada uma característica da espécie, como forma de sobrevivência em condição de estresse.

A taxa de crescimento relativo (TCR) é definida por Aguiar Netto et al. (2000) como um índice de eficiência, já que representa a capacidade da planta em produzir material novo. A TCR decresceu ao longo do ciclo (Figura 1C e D), o que segundo Ferrari et al. (2008) era esperado, pois com o acréscimo da fitomassa seca acumulada pelas plantas, aumenta a necessidade de fotoassimilados para a manutenção das estruturas já formadas, diminuindo a quantidade disponível para o crescimento. Também, de acordo com Urchei et al. (2000), a redução desse índice fisiológico no final do ciclo pode ser explicada pelo autosombreamento e pelo menor incremento da área foliar ao longo do ciclo, além da elevação da atividade respiratória. Cometti et al. (2008) sugerem que o declínio da TCR indica a aproximação da senescência, momento em que a assi- milação líquida passa a ser negativa.

$\mathrm{O}$ valor de TCR superior para a cultivar Cherry conduzida no substrato 5 , em relação aos demais substratos (Figura $1 \mathrm{D}$ ), indica maior eficiência na conversão de fitomassa seca por unidade de tempo, em relação à fitomassa inicial. Essa eficiência parece estar relacionada principalmente à maior taxa de fotossíntese líquida, já que a razão de área foliar praticamente não se alterou nos diferentes substratos.

A cultivar Red conduzida no substrato 3 apresentou maior taxa de crescimento relativo e taxa de fotossíntese líquida (Figura 1C e E), comparada a Cherry (Figura 1D e F), indicando que a cultivar Red foi mais eficiente na produção da fitomassa seca quando conduzida nesse substrato. Como as diferenças para a razão de área foliar foram menos perceptíveis, é possível inferir que a TCR não foi influenciada pelo tamanho da área fotossintética, e sim pela eficiência fotossintética.

Analisando as características do substrato 5 (Tabela 1) verificou-se valores iniciais de $\mathrm{pH}$ elevados para a gérbera $(7,58)$ o que possivelmente tenha interferido no desenvolvimento inicial das plantas. A redução do $\mathrm{pH}$ ao longo do ciclo e valores finais de 6,89, permitiu que as plantas recuperassem seu desenvolvimento, já que as características físicas eram adequadas, além da elevada disponibilidade de $\mathrm{K}$, o nutriente absorvido em maiores quantidades pela cultura da gérbera (Ludwig et al., 2008). Segundo recomendações obtidas na literatura, o $\mathrm{pH}$ para gérbera pode ser mantido entre 5,5 e 6,5 (Rogers \& Tjia, 1990), enquanto outros autores relatam que o $\mathrm{pH}$ acima de 6,0 provoca diminuição da produção (Sonneveld \& Voogt, 1997; Savvas \& Givas, 2002).

A taxa de assimilação líquida (TAL) representa o balanço entre o material produzido pela fotossíntese e o perdido pela respiração, expressando a eficiência das folhas na produção de fitomassa seca e a estimativa da fotossíntese líquida (Benincasa, 2003). O decréscimo na fotossíntese líquida observada ao longo do ciclo de crescimento da cultura da gérbera (Figura 1E e F) está associado ao auto-sombreamento promovido pela sobreposição das folhas, a redução da 
Tabela 2. Valores médios para fitomassa seca da folha (FSF), fitomassa seca da inflorescência (FSI), número de folhas (NF), diâmetro de planta (DP), área foliar (AF), tamanho da folha (TF), número de inflorescências (NI) e diâmetro de inflorescência (DI) aos 43 DAA em cultivares de gérbera de vaso em função dos substratos (leaf dry phytomass (FSF), inflorescence dry phytomass (FSI), leaf number (NF), plant diameter (DP), leaf area (AF), leaf size (TF), inflorescence number (NI) and inflorescence diameter (DI) at 43 DAA of gerbera cultivars, depending on substrates). Botucatu, UNESP. 2008.

\begin{tabular}{lllllcccl}
\hline Substrato & $\mathbf{F S F}(\mathbf{g})$ & $\mathbf{F S I}(\mathbf{g})$ & $\mathbf{N F}$ & $\mathbf{D P}(\mathbf{c m})$ & $\mathbf{A F}\left(\mathbf{d m}^{\mathbf{2}}\right)$ & $\mathbf{T F}\left(\mathbf{d m}^{\mathbf{2}}\right)$ & $\mathbf{N I}$ & $\mathbf{D I}(\mathbf{m m})$ \\
\hline 1 & $5,1 \mathrm{c}$ & $4,2 \mathrm{ab}$ & $22,0 \mathrm{~b}$ & $25,4 \mathrm{bc}$ & $7,2 \mathrm{c}$ & $0,33 \mathrm{bc}$ & $3,5 \mathrm{a}$ & $78,0 \mathrm{ab}$ \\
2 & $3,9 \mathrm{~d}$ & $3,4 \mathrm{~b}$ & $19,3 \mathrm{~b}$ & $24,1 \mathrm{c}$ & $5,4 \mathrm{~d}$ & $0,28 \mathrm{c}$ & $3,1 \mathrm{a}$ & $73,0 \mathrm{~b}$ \\
3 & $6,0 \mathrm{bc}$ & $4,7 \mathrm{a}$ & $23,9 \mathrm{ab}$ & $27,4 \mathrm{~b}$ & $9,0 \mathrm{~b}$ & $0,39 \mathrm{ab}$ & $3,8 \mathrm{a}$ & $77,1 \mathrm{ab}$ \\
4 & $8,6 \mathrm{a}$ & $4,4 \mathrm{ab}$ & $28,5 \mathrm{a}$ & $32,8 \mathrm{a}$ & $12,3 \mathrm{a}$ & $0,44 \mathrm{a}$ & $2,8 \mathrm{a}$ & $87,1 \mathrm{a}$ \\
5 & $6,7 \mathrm{~b}$ & $4,0 \mathrm{ab}$ & $24,3 \mathrm{ab}$ & $31,2 \mathrm{a}$ & $9,7 \mathrm{~b}$ & $0,41 \mathrm{a}$ & $2,6 \mathrm{a}$ & $88,4 \mathrm{a}$ \\
\hline Cultivar & & & & & & & \\
\hline Red & $5,3 \mathrm{~B}$ & $4,1 \mathrm{~A}$ & $23,9 \mathrm{~A}$ & $26,5 \mathrm{~B}$ & $8,2 \mathrm{~B}$ & $0,34 \mathrm{~B}$ & $3,9 \mathrm{~A}$ & $80,3 \mathrm{~A}$ \\
Cherry & $6,9 \mathrm{~A}$ & $4,2 \mathrm{~A}$ & $23,3 \mathrm{~A}$ & $29,9 \mathrm{~A}$ & $9,3 \mathrm{~A}$ & $0,40 \mathrm{~A}$ & $2,5 \mathrm{~B}$ & $81,1 \mathrm{~A}$ \\
\hline CV $(\%)$ & 12,40 & 20,36 & 16,40 & 6,30 & 12,27 & 14,20 & 40,94 & 11,34 \\
\hline
\end{tabular}

Médias seguidas pela mesma letra na coluna, sendo minúsculas para substratos e maiúsculas para cultivares não diferem entre si pelo teste Tukey a $5 \%$ (means followed by the same letters in the same column, being lowercase to substrates and uppercase to cultivars did not differ by the Tukey's test at $5 \%$ ).

eficiência fotossintética e aumento das perdas respiratórias.

A redução da TAL foi menos acentuada para as duas cultivares de gérbera desenvolvidas nos substratos 1 e 2 (Figura 1E e F). Essa informação parece estar relacionada principalmente com a maior distribuição de fitomassa seca para as inflorescências (Tabela 2) e redução do incremento da área foliar e sombreamento. Outro fator que pode ter contribuído para as menores reduções da TAL nesses substratos é o reduzido tamanho das folhas, 0,33 e 0,28 $\mathrm{dm}^{2}$ para os substratos 1 e 2 , respectivamente (Tabela 2), com conseqüente redução do auto-sombreamento. A maior queda da TAL para plantas submetidas ao substrato 4 é justificada pela maior área foliar, devido ao efeito do sombreamento nas folhas inferiores.

Os valores de $\mathrm{pH}$ podem também ter influenciado o crescimento das plantas de gérbera nos substratos $1 \mathrm{e}$ 2 , entretanto, pelo baixo valor $(5,13 \mathrm{e}$ 4,81 , respectivamente). De acordo com Fermino (1996) valores inadequados de $\mathrm{pH}$ podem afetar o desenvolvimento das plantas, principalmente sob acidez excessiva. Plantas cultivadas em ambientes ácidos têm quantidades menores de nutrientes à sua disposição, além de ficarem sujeitas à maior absorção de elementos tóxicos como $\mathrm{Al}$ e $\mathrm{Mn}$, este último, já encontrado em quantidades superiores no substrato 2. Para o cultivo de gérbera o $\mathrm{pH}$ mínimo ideal deve ser 5,5 (Cavins et al., 2000; Rogers \& Tjia, 1990).

Apesar das características iniciais de porosidade total e de aeração estarem adequadas para o desenvolvimento da maioria das culturas (De Boodt \& Verdonck, 1972), a presença de solo de textura argilosa na composição dos substratos 1 e 2 pode ter promovido uma maior compactação ao longo do ciclo. Aliado a isso, a elevada densidade seca desses substratos $\left(540 \mathrm{~kg} \mathrm{~m}^{-3}\right)$ dificulta o crescimento radicular, especialmente em vasos com capacidade para um litro e 11,5 cm de altura. Kämpf (2000) recomenda utilizar substratos com densidade seca de 250 a $400 \mathrm{~kg} \mathrm{~m}^{-3}$ para vasos de até $15 \mathrm{~cm}$ de altura, indicando que altas densidades limitam o crescimento das plantas.

A redução da TAL foi mais acentuada quando as plantas foram conduzidas nos substratos 3 e 4 para Red e 4 para Cherry, indicando que estes substratos contribuem para o rápido crescimento das plantas de gérbera, que é uma característica vantajosa para o produtor, pelo maior fluxo de plantas e retorno econômico. Para obter melhor qualidade das plantas desenvolvidas nos substratos 1 e 2, seria necessário proceder o desbaste dos botões florais durante um período superior a 29 DAA, o que acarretaria em atraso na produção.

As características de qualidade estética variam entre os tipos de planta ornamental e para flor envasada, há que se considerar a formação da folhagem e da inflorescência. O número de inflorescências não variou entre os substratos, entretanto o diâmetro destas foi superior para os substratos 4 e 5 e inferior no substrato 2, a área foliar foi superior para aquelas produzidas no substratos 4, o que caracteriza a formação de um conjunto adequado de vaso (Tabela 2 ).

A análise de crescimento pode ser utilizada como uma importante técnica para a avaliação das adaptações da planta em diferentes condições do meio de cultivo. Assim, pode-se inferir que as plantas de gérbera tiveram limitação de crescimento ao serem conduzidas com os substratos 1 e 2, que continham solo na sua composição, especialmente pelas suas características químicas e físicas inadequadas.

Com base nos resultados obtidos foi possível concluir que as plantas de gérbera apresentam melhor desenvolvimento quando conduzidas no substrato 4 (30\% casca de pinus $+30 \% \mathrm{C}_{1}+20 \%$ fibra de coco granulada $+20 \%$ fibra de coco mista). A seleção de substratos adequados ao desenvolvimento de gérbera deve considerar principalmente as características químicas e físicas dos mesmos. Para as cultivares Red e Cherry, o $\mathrm{pH}$ inferior a 5,5 e superior a 7,0 foi inadequado para o crescimento, bem como densidade seca superior a $530 \mathrm{~kg} \mathrm{~m}^{-3}$.

\section{AGRADECIMENTOS}




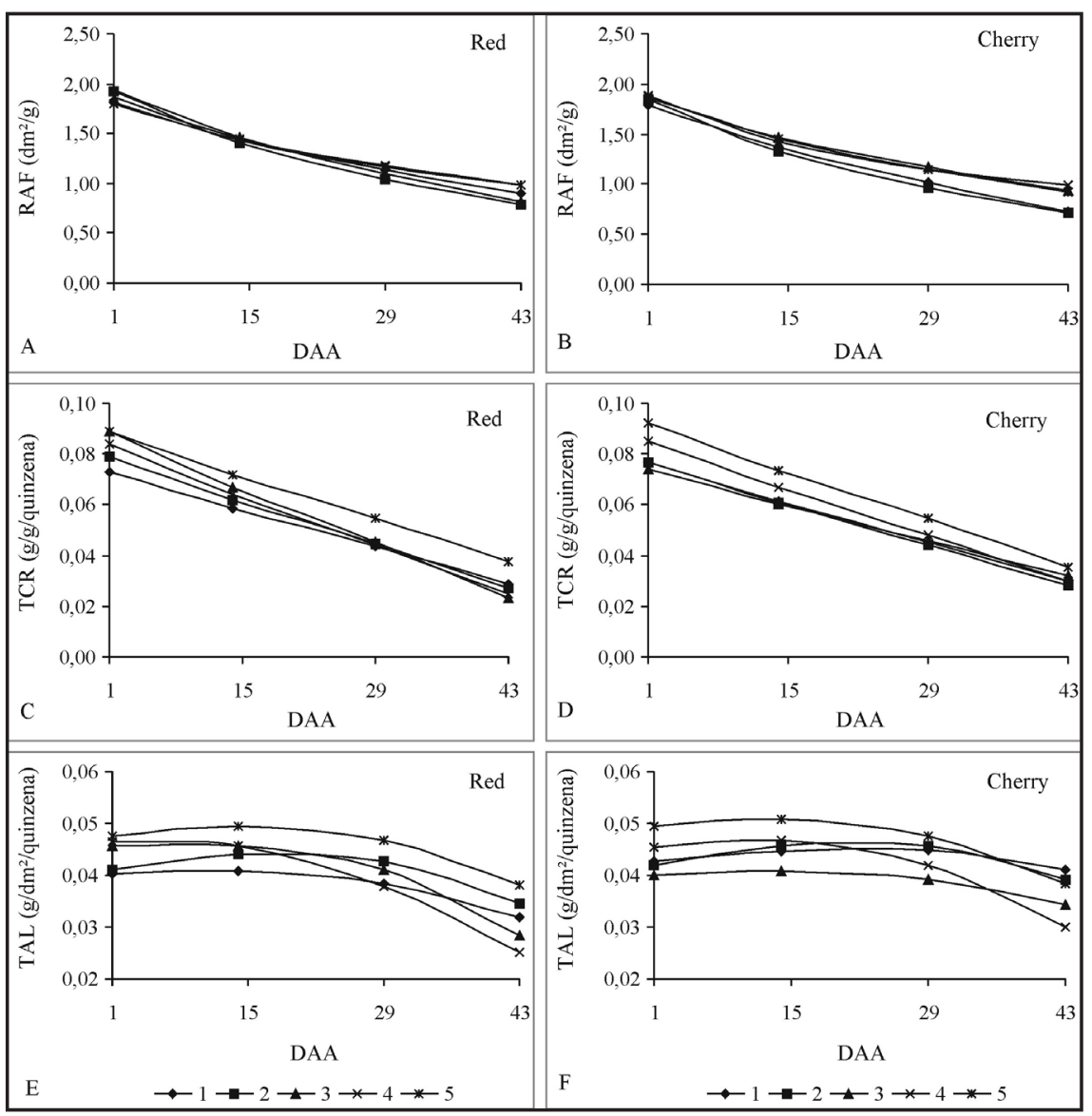

Figura 1. Valores médios de razão da área foliar (RAF) (A e B), taxa de crescimento relativo (TCR) (C e D) e taxa de assimilação líquida (TAL) (E e F) em plantas de gérbera conduzidas em diferentes substratos, ao logo dos dias após a aclimatação (DAA) (leaf area ratio (RAF) $(\mathrm{A}$ and $\mathrm{B})$, relative growth rate (TCR) $(\mathrm{B}$ and $\mathrm{C})$ and net assimilation rate (TAL) (E and F) of gerbera plants conducted with different substrates in days after acclimation (DAA)). Botucatu, UNESP. 2008.

À Capes pela concessão de bolsa ao primeiro autor, e ao CNPq pela concessão de bolsa aos demais autores. Às empresas Sakata e Steltenpool pela contribuição no desenvolvimento da pesquisa.

\section{REFERENCIAS}

AGUIAR NETTO AO; RODRIGUES JD; PINHO SZ. 2000. Análise de crescimento na cultura da batata submetida a diferentes lâminas de irrigação. Pesquisa Agropecuária Brasileira 35: 901-907.

BELLÉ S. 2001. Escolha do substrato. In KÄMPF AN (coord). Manutenção de plantas ornamentais para interiores. Porto Alegre: Rígel. 112p.

BENINCASA MMP. 2003. Análise de crescimento de plantas (noções básicas). Jaboticabal: FUNEP. 41p.

BRASIL. Instrução Normativa n.17, de 21 de maio de 2007. Aprova os Métodos Analíticos Oficiais para Análise de Substratos e Condicionadores de Solos. Diário Oficial da União, Brasília, 24 maio. 2007. Seção 1, p.8.
CAVINS TJ; WHIPKER BE; FONTENO WC; HARDEN B; McCALL I; GIBSON JL. 2000. Monitoring and managing $\mathrm{pH}$ and $\mathrm{EC}$ using the PourThru extraction method. Raleigh: Horticulture Information. $17 \mathrm{p}$.

CHARLO HCO. 2008. Análise de crescimento e marcha de acúmulo de nutrientes na cultura do pimentão, cultivado em substrato. Jaboticabal: UNESP-FCAV. 66p. (Tese mestrado).

COMETTI NN; MATIAS GCS; ZONTA E; MARY W; FERNANDES MS. 2008. Efeito da concentração da solução nutritiva no crescimento da alface em cultivo hidropônicosistema NFT. Horticultura Brasileira 26: 262-267.

De BOODT M; VERDONCK O. 1972. The physical properties of the substrates in

FERRARI TB; FERREIRA G; ZUCARELI V; BOARO CSF. 2008. Efeito de reguladores vegetais nos índices da análise de crescimento de plântulas de maracujazeiro-doce (Passiflora alata Curtis). Biotemas 21: 45-51.

FERMINO MH. 1996. Aproveitamento de Resíduos Industriais e Agrícolas como alternativas de Substratos Horticolas. Porto Alegre: UFRGS. 91p. (Tese mestrado).

FERREIRA DF. Análises estatísticas por horticulture. Acta Horticulturae 26: 37-44. meio do Sisvar para Windows versão 4.0. 2000. In: REUNIÃO ANUAL DA REGIÃO BRASILEIRA DA SOCIEDADE INTERNACIONAL DE BIOMETRIA, 45. Anais...UFSCar, São Carlos. p.255-258.

FONTES PCR; DIAS EN; SILVA DJH. 2005. Dinâmica do crescimento, distribuição de matéria seca na planta e produção de pimentão em ambiente protegido. Horticultura Brasileira 23: 94-99.

INFOAGRO. El cultivo de la gerbera. 2005. Madrid: Infoagro System, [s.d.]. Disponível em: <http:/www.infoagro.com/flores/flores/ gerbera.htm>. Acesso em 13 de abril de 2005.

KÄMPF AN. 2000. Produção comercial de plantas ornamentais. Guaíba: Agropecuária. $254 \mathrm{p}$.

LENZI A; RINALDI M; BIOCCA M; MALETTA M; PERGOLA G. 1998. Soilless cultivation of Gerbera in various substrates and two fertirrigation regimes [Gerbera jamesonii Bolus]. Colture-Protette 27: 34-38. Disponível em CAB-ABSTRACTS.

LUDWIG F; FERNANDES DM; MOTA PRD; VILLAS BÔAS RL. 2008. Macronutrientes em cultivares de gérbera sob dois níveis de fertirrigação. Horticultura Brasileira 26: 68-73.

MASCARINI L. Gerbera cultivation in growing media. 1998. Horticultura Internacional 6: 86-88.

MERCURIO G. 2002. Gerbera cultivation in greenhouse. The Netherlands: Schreurs. 206p.

PORTES TA; CASTRO JUNIOR LG. 1991. Análise de crescimento de plantas: Um programa computacional auxiliar. Revista Brasileira de Fisiologia Vegetal 3: 53-56.

RAIJ BV; ANDRADE JC; CANTARELLA H; QUAGGIO JA. 2001. Análise química da fertilidade dos solos tropicais. Campinas: IAC. 285 p.

ROGERS MN; TJIA BO. 1990. Gerbera production for cut flowers and pot plants. Portland: Timber Press. 116p.

SAVVAS D; GIZAS G. 2002. Response of hydroponically grown gerbera to nutrient solution recycling and different cation ratios. Scientia Horticulturae 96: 267-280.

SILVA TGG; ZOLNIER S; GROSSI JAS; BARBOSAJG; MOURA CRW; MUNIZ, MA. 2009. Crescimento do girassol ornamental cultivado em ambiente protegido sob diferentes níveis de condutividade elétrica de fertirrigação. Revista Ceres 56: 602-610.

SONNEVELDC; ELDEREN CW. 1994. Chemical analysis of peaty growing media by means of water extraction. Communication on Soil Science and Plant Analysis 25: 3199-3208.

SONNEVELD C; VOOGT W. 1997. Effects of $\mathrm{pH}$ and $\mathrm{Mn}$ application on yield and nutrient absorption with rockwool grown gerbera (refereed). Acta Horticulturae 450: 139-147.

URCHEI MA; RODRIGUES JD; STONE LF. 2000. Análise de crescimento de duas cultivares de feijoeiro sob irrigação, em plantio direto e preparo convencional. Pesquisa Agropecuária Brasileira 35:497-506. 